\title{
A System Design of Opened Communication Principle Laboratory
}

\author{
Minghou Wu, Feng Xie, Zhenrong Zhang, Zhihui Ge \\ School of Computer and Electronics and Information \\ Guangxi University \\ Guangxi Nanning \\ e-mail: minghouwu@gmail.com
}

\begin{abstract}
The paper has presented a new method of communication principle experiment reforming, and designed a new system of opened communication principle laboratory. This new method has solved the problems current existing effectively, which includes low utilization of experiment equipment, high-grade instruments ware not shared, the content of experiment is rigid and the experiment time is not inflexible. The practice teaching shows that this system can improve the utilization of laboratory efficiently and provided a better platform in promoting students' interest, stimulating students to think independently, cultivating students' basic experimental ability, innovative ability and research-based experimental design ability.
\end{abstract}

Keywords-communication principle; experiment reforming; experiment platform

\section{INTRODUCTION}

Principle of communication is one of the most important subjects in communication professional teaching, which got a rapid development in the wave of communication principle teaching. With the deepening of teaching reform and the continuous development of communication technology, communication principle experiment has become an increasingly important role in students' practice ability and innovation ability training [1]. While on the study of communication principle experiment theaching has made certain achievements at home and abroad, and some companies have also produced a number of advanced experimental equipment of communication principle. But these devices have to rely on independent digital or analog oscilloscope, can't connect to the internet, Can't self-monitor. It is not conducive to the development of the open laboratory, but also would increase the cost of experiment and laboratory construction.

With the development of the Internet of things, embedded devices network become the trend of the future. Especially, with the expansion of the EDA technology and programmable logic devices technology, learning simulation and design of algorithm is one of the skills that students of electronic communications must to master [2][3].

In this paper, we start from teaching practice, consider the teaching evaluation and the feedback of students. Summarize the problems which existed in the construction of communication principle laboratory in section II. In view of the problem, we discussed the solutions in section III. In the section IV we discussed the system structure of the whole experimental system and descript the function and implementation of each part.

\section{PROBLEMS EXISTING}

With the deepening reform of the communication principle experiment, the reform has got lots of achievements in cultivating the practice ability and innovation ability of students [4]. But still be of some problems in the teaching of communication principle experiment and the laboratory construction. We have listed that as below.

\section{A. Obsolete experiment contents and lack of innovation}

The content of the communication principle between the traditional experimental verification is given priority to with textbook theory. Obsolete experiment contents not means that the verified experiment is not important, it ments the contents of experiment is just rooted in the textbook and many students reflect that some of those experiments is very boring and unchallenged. And more important is that unmatched with the development of communication technology and went against the innovation of students.

\section{B. A lower resource utilization of experiment}

According to the survey, we foud that most stduents don't know what experiment resource they can use and don't know what time is free about the laboratory. Some of the students think the experiment time is insufficient. There is no abundant time to do the experiment which they want to do. And most time the laboratory is idle. It means that has a very low resource utilization of experiment. In a sense, it is a waste of expriment resources.

\section{Disadvanced laboratory management}

Advanced regime of laboratory management is the best way to integrate resouces of laboratory. But as we survey result show that the laboratory management of most laboratories is incompact, and be shorten in effective manage system builting. Such as the experiment kits can't connect with local serves, these is no system for Managing experiment equipment, monitoring equipment running status, accept reservation request from students, managing students experiment report, etc. That is not a good new for the construction of laboratory and integration the resources of laboratory. 


\section{Half-baked experiment teaching method}

As we know, experiment is a very important part in communication principle teaching, and the ability of different students is almost different. But the experiment teaching method is almost do the verification experiment on communication principle experiment kits, and simulate the algorithm and design with EDA tools. However, this experiment method has become a serious impediment to the cultivation of the students' personal abilities and interests.

All of the above is a summary of our survey and teaching practice. Based on those problems we designed a system of opened laboratory for communication experiment laboratory. We will discuss that in the follow sections in detail.

\section{THE SOLUTONS}

In this section we will discuss how to solve the problems that we list in section II.

Firstly, we should delete the experiment contents which are obsolete and not matched with the development of communication technology. We needn't to verify all knowledge point in the textbook. The Validation experiments we did just to let the students understand the fundamental of communication system and learn how to operate of basic experimental instrument. So reduce the proportion of verification experiment, and add some contents of comprehensive experiment, design experiment and innovative experiment are very nessesary.

Secondly, we need to create a system for collecting and summary the basic information of laboratory, such as what quipments are spare, what work the equipment can finish and what time is idle for students to do their jobs, etc. By this way students can get the information of laboratory comprehensively, and they can make full use of their spare time to finish their experiment in the laboratory. But all of this needs a platform to publish the information to students and process the students' predetermine.

Thirdly, we should built a fully functional database, which is use to record the basic information of equipments and integrate a data base to record the data of different students' experiment and operation steps. That is good for students to finish their experiment report base on the experiment data and is also good for teacher to guide the students' experimental operation. On the other hand, a database is very necessary for teachers to manage the laboratory and guide students finish their experiment and rescue students' mistake operation immediately.

Finally, half-baked experiment method already can't meet the demand of different students. So, gathering different methods to increase the diversity of experiment teaching is benefit for increasing the interest of students and meeting the need of different students. For example, we can use the traditional communication experiment kits for validation experiments, and use simulation tools for simulating the comprehensive experiment [5], and use EDA tools for design experiment and innovative experiment [6]. FPGA is a good platform for do all of the experiments, because of its reconfigurable characteristic [8].

\section{SYSTEM ARCHITECTURE}

Based on the solutions we discussed in section III, we designed an opened system for communication principle experiment laboratory. The system sues a top-down design ideas and modular design thought, and uses the advanced Wechat public platform and system-on-chip technology based on FPGA. Teachers can manage the laboratory, release information with the Wechat public platform and students can make an appointment with teacher for experiment time to do what they want to do. The architecture of this system was shown in Fig.1.

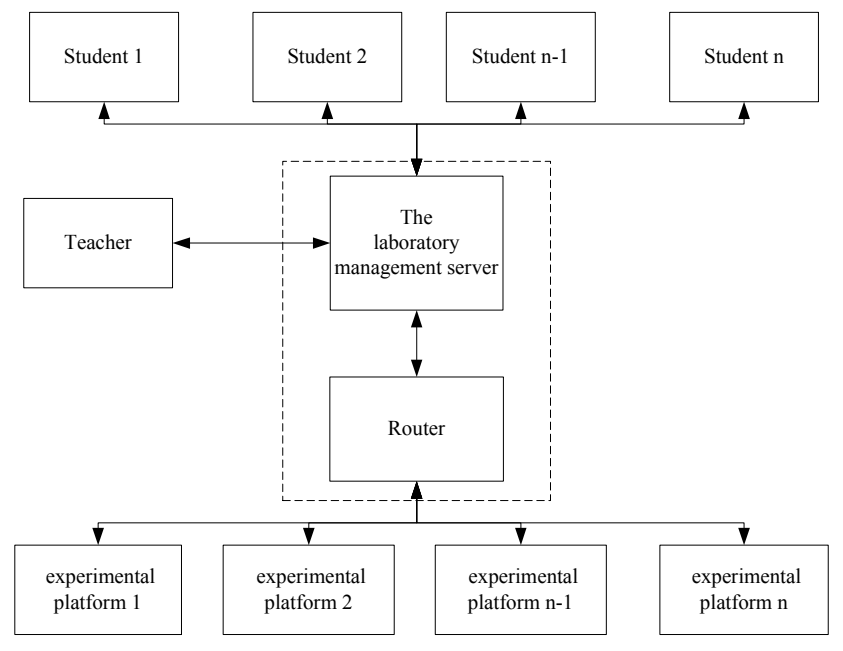

Figure 1. System structure diagram

\section{A. The laboratory management server}

The laboratory management server is the center of the opened laboratory system, which works based on a database and Wechat public platform [7]. Its use for saving all the data generated by the teachers and students and processing information interact with Internet. It consists of the following three parts. It was shown in the Fig.2.

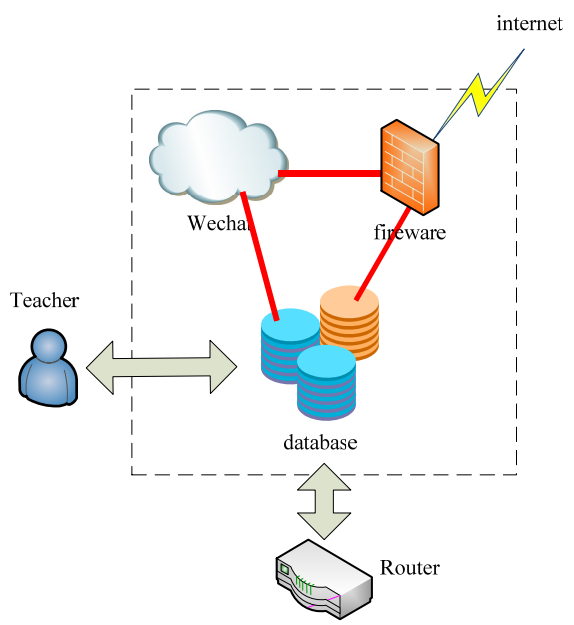

Figure 2. Managerment server structure chart 
The management sever consists of three function parts. The most important part is the database, which responsible for storing all data of laboratory. It includes the basic information of experiment equipment, such as the product serial number and simple functional description, etc. And it also stores experiment data, steps of experiment operation, status information of experiment equipment, the experiment report of students and the booking request message from the students, etc. The database is the center for processing different kinds of data.

The Wechat public platform use to push information of the laboratory, and student can receive the information from their mobile phones or personal computers. The information pushed almost about what experiment equipment are spare and how it worded for experimenting, what time it opened for students. Students who can take an order to do the experiment they want to. By this way, there is a bridge between the students and laboratory. That is good way to improve the source utilization and it is also flexible for students to arrange experiment content and time.

The fireware is a bridge between the management sever and internet. All data exchange between database and external parts must pass through it. And it provides a protection for communication between laboratory and outer equipment. So it is a very important part of the management server.

\section{B. Router}

Router is internal bridge between the management server and experiment platform. On one hand, when somebody do experiment at the experimental paltform, the experiment data and $\log$ file of operition will be sent to the database through the router. On the other hand, the management sent detect message to the experimental platform to detect which platform is spare and how many platform can be used. The platform will sent a busy message if it was working. All of this process is finished automatically. And TCP/IP protocol was used in the local communication.

\section{Experimental platform}

Experiment platform is almost the most important part of communication principle experiment teaching. It takes us most time to design this part. In order to meet the need of verification experiments, comprehensive experiments, designing experiments and innovative experiment, the platform adopts the modular design thought and advanced programmable technology.

We designed the platform based on Basic model of communication system as shown in Fig.3. As it shows, we know that it is just a basic model of communication system. In fact, the real communication system is more complex than the structure diagram. In order to provide a functional platform for different experiment level, we designed basic models for verification experiment, and provide a unified opened interface. It is very flexible for users to integrate modules to do a comprehensive experiment or redesign the modules for a designing experiment.

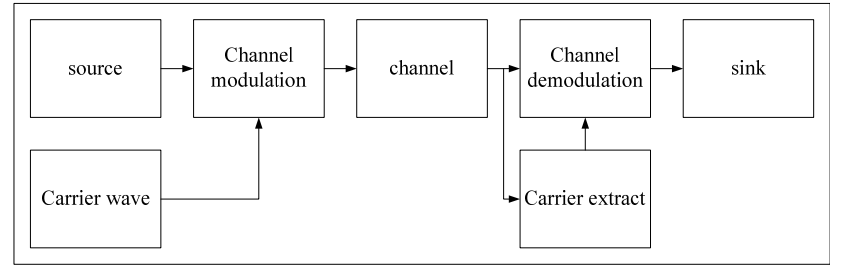

Figure 3. Communication system structure diagram

In order to uniform interface standard and facilitate the secondary development, we defined a standard interface for different models to ensure that it is compatible with the ready-made or custom design module. Analog model and digital moduel have different interfaces, and they were defined in detail as shown in table I.

TABLE I. INTERFACE OF DIFFERENT MODEL

\begin{tabular}{|l|l|l|}
\hline \multicolumn{1}{|c|}{ category } & \multicolumn{1}{c|}{ Analog } & \multicolumn{1}{c|}{ Digital } \\
\hline voltage & $3.3 \mathrm{~V}$ & $3.3 \mathrm{~V}$ \\
\hline bitwidth & $1 \mathrm{bit}$ & $16 \mathrm{bits}$ \\
\hline GND & Analog ground & Digital ground \\
\hline Width of spread head & $100 \mathrm{mail}$ & - \\
\hline ADC interface & $1 \mathrm{bit}$ & $16 \mathrm{bits}$ \\
\hline DAC interface & $1 \mathrm{bit}$ & $16 \mathrm{bits}$ \\
\hline
\end{tabular}

According to the system function, we divided system into five parts. It was shown in Fig.4.

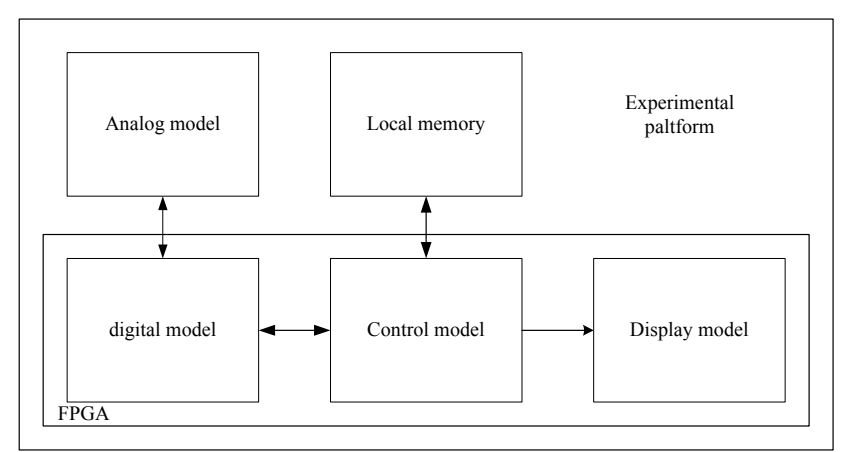

Figure 4. Experimental platform structure diagram

As the fig. 4 shows, the analog part and local memory were designed on PCB board and the digital part, control model and display model were realized in a chip of FPGA. Thanks to the modular design and FPGA reconfigurable characteristics, we can do a verification experiment with ready-made module. And we also can design a comprehensive experiment, which include the whole communication system with the module designed by ourselves. As a mater of fact, it is a good for students to divergent thinking and cultivating their ability of independent thinking, literature review, hands-on practice, analyzing and resolving problems.

- Analog model. Although, at present most of the communication systems are digital. But analog communication as the basis of digital communication, which can't be ignored in the teaching of communication principle experiment. 
Students will have a clearly understand of the overall structure of the communication system by learning, analyzing the model of analog communication. Designing the analog model parts of communication independently can improve students' ability in analog circuit design and increase students' ability on analyzing of analog signal processing. Now, there are a lot of mature analog circuit simulation and design software at home and abroad, such as Altium Designer, Labview, PowerPCB, etc. Using the software, students can design the circuit for modeling and simulation, verification principle of the circuit is correct or not.

- Digital model. This model was designed in a chip of FPGA with verilog HDL. It contains a basic prototype of digital communication, and it also control the translating of digital model and analog model. Ditital communication is the trend of future. Familiar with EDA tools to design ditigal circuit has become one of must master skills of communication professional students. Base on this model, students can analysis the basic principle and mathematical model of digital communication, described that with HDL language, then use EDA software convert it to netlist file, finally download the netlist to the FPGA. Reconfigurable feature, allowing students to redesign prototype flexibly and it is very effective to stimulate the intrest of students.

- Control model. Control model is the core of this platform, which implemented with a SOPC architecture. We use a Nios II, a soft IP core, as the MCU of the platform. It is mainly used for control waveform display and data communication with the server. And it includes a soft core processor, PIO control module, FLASH, SDRAM control module, USB VGA control module. There is a simple ROTS system running in this model, which was used for task scheduling and management of the whole system. Students can save the experimental data through the USB port.

- Local memory. There are two memories in this part. One is a FLASH memory for storing the soft code and configured data. The other is a SDRAM memory for the normal running of the software.

- Display model. This model consist of two parts, a timing sequence generate module and a DMA module. The timing sequence generate module generate the control signals for VGA display. And in order to release the MCU, we added a DMA in this model for transmitting data from the SDRAM memory to VGA data ports. This model can display data of four channels.

We recommend student that befor design a custom system experiment in the platform, you'd better simulate your design with EDA software, such as MATLAB and system View, etc. By this way, we can validate our design experiment algorithm is correct or not. It can improve the success rate of our experiment [9].

\section{CONCLUSION}

This paper presented a new method of communication principle experiment reforming, and designed a new system of opened communication principle laboratory. We summarized the main problems existing in the experimental teaching, and discussed the primary cause of each problem in detail. Based on analysis result, we presented some solutions for those we summarized above. Finally, we design an opened laboratory system for solving those problems in practice. We have used this system in our communication principle experiment teaching, the experiment teaching evaluation shows that it enhanced the laboratory management and improved the utilization of laboratory resources. And from the feedback of students indicate that it is very flexible and more interesting, more challenge than before.

\section{ACKNOWLEDGMENTS}

Our works are supported by Guangxi Ministry of Education Foundation (2013JGB113) and Guangxi Science Foundation(2012GXNSFAA053223,2012GXNSFAA05322 6,2013GXNSFCA019019).

\section{REFERENCES}

[1] X. Zhang, and M.Huang, Exploration and Practice on the Research Teaching of Communication Principle Course. In Circuits, Communications and System (PACCS), IEEE 2011 Third PacificAsia Conference on, Vol.6, 2011, pp. 1-4.

[2] SUN. Ai-jing, and LIU. Yu, "Study on Experimental Teaching of Communication Principle Based on Software Simulation." Research and Exploration in Laboratory, Vol.047, Jan 2010.

[3] C. H. E. N. Zhao, "The important of teaching in the principle of communication based on the simulation experiments by MATLAB." Experimental Technology and Management, Vol.5. 2007.

[4] MA. Dong-mei, and Zheng-wei ZHU, "Reform and exploration on the experimental teaching of communication principle." Laboratory Science Vol.4, Iss.026, 2010.

[5] SUN Y, ZHANG L, GENG Y. Research on virtual experiment simulation system in the course of communication principle [J]. Laboratory Science, Vol.6, Iss.036, 2010.

[6] XU Y, SHUANG K, JIANG S. Study on Experimental Teaching of Communication Principle. Research and Exploration in Laboratory, Vol.6, Iss.094, 2011.

[7] Jinhua X, Lihong H, Research on Information Service Mode of the Library Based on WECHAT.

[8] Hauck S, DeHon A, Reconfigurable computing: the theory and practice of FPGA-based computation. Morgan Kaufmann, 2010.

[9] Jia K, Lv Y, Hou L, Applied Research of EDA Technology in Course of Digital Communication Principle//Education Technology and Computer Science, 2009. ETCS'09. First International Workshop on. IEEE,Vol.3, pp.198-200, 2009. 